\title{
Erratum to: A new species of Pseudostomella (Gastrotricha, Thaumastodermatidae) from Brazil
}

\author{
Thiago Q. Araujo • Maria Balsamo • André R. S. Garraffoni
}

Published online: 23 August 2014

(C) Senckenberg Gesellschaft für Naturforschung and Springer-Verlag Berlin Heidelberg 2014

Erratum to: Mar Biodiv

DOI 10.1007/s12526-013-0196-x

Pseudostomodella in the title and along the text is incorrect.

The correct form is Pseudostomella.

The online version of the original article can be found at http://dx.doi.org/ 10.1007/s12526-013-0196-x.

T. Q. Araujo $(\bowtie)$

Departamento de Zoologia, Instituto de Ciências Biológicas,

Universidade Federal de Minas Gerais, Av. Antônio Carlos, 6627,

31270-901 Belo Horizonte, MG, Brazil

e-mail: araujotq@gmail.com

\section{Balsamo}

Dipartimento di Scienze della Terra, della Vita e dell'Ambiente,

Università di Urbino, Campus Scientifico, loc. Crocicchia, Urbino,

Italy

\section{A. R. S. Garraffoni}

Laboratório de Microinvertebrados de Água Doce, Departamento de

Ciências Biológicas, Universidade Federal dos Vales do

Jequitinhonha e Mucuri, Campus JK. Rodovia BR-367,

39.100-000 Diamantina, MG, Brazil 